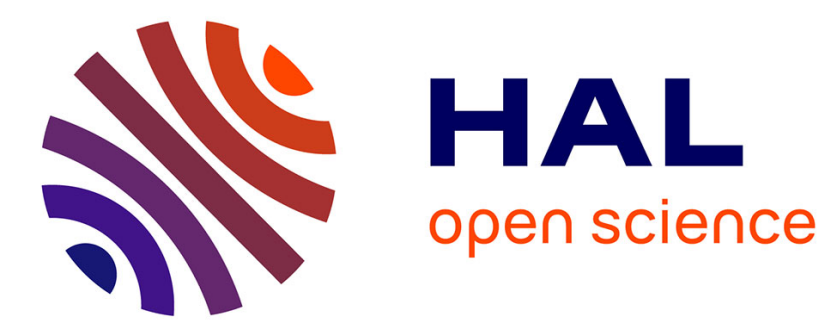

\title{
Is the assessment of submucosal invasion still useful in the management of early rectal cancer? A study of 91 consecutive patients
}

C. Debove, M. Svrcek, S. Dumont, N. Chafai, E. Tiret, Y. Parc, J. H. Lefèvre

\section{- To cite this version:}

C. Debove, M. Svrcek, S. Dumont, N. Chafai, E. Tiret, et al.. Is the assessment of submucosal invasion still useful in the management of early rectal cancer? A study of 91 consecutive patients. Colorectal Disease, 2017, 19 (1), pp.27 - 37. 10.1111/codi.13405 . hal-01504652

\section{HAL Id: hal-01504652 https://hal.sorbonne-universite.fr/hal-01504652}

Submitted on 10 Apr 2017

HAL is a multi-disciplinary open access archive for the deposit and dissemination of scientific research documents, whether they are published or not. The documents may come from teaching and research institutions in France or abroad, or from public or private research centers.
L'archive ouverte pluridisciplinaire HAL, est destinée au dépôt et à la diffusion de documents scientifiques de niveau recherche, publiés ou non, émanant des établissements d'enseignement et de recherche français ou étrangers, des laboratoires publics ou privés. 
061-2016.R1

Original Article

Is the assessment of submucosal invasion still useful in the management of early rectal cancer? A study of 91 consecutive patients

Clotilde Debove (MD) ${ }^{1}$, Magali Svrcek $(\mathrm{MD}, \mathrm{PhD})^{2}$, Sylvie Dumont ${ }^{3}$, Najim Chafai (MD) ${ }^{1}$, Emmanuel Tiret $(\mathrm{MD}, \mathrm{PhD})^{1}$, Yann Parc $(\mathrm{MD}, \mathrm{PhD})^{1}$, Jérémie H. Lefèvre $(\mathrm{MD}, \mathrm{PhD})^{1}$

${ }^{1}$ Department of Digestive Surgery, St Antoine Hospital (AP-HP), Paris VI University, Paris, France

${ }^{2}$ Department of Pathology, St Antoine Hospital (AP-HP), Paris VI University, Paris, France

${ }^{3}$ Pierre et Marie Curie University, Paris VI University, Paris, France

No financial disclosure or conflict of interest.

Running-Head: Lymph node metastasis in early rectal cancer

Address for correspondence and reprints:

Pr. Jérémie H. Lefèvre, M.D., Ph.D., Service de Chirurgie Digestive, Hôpital Saint-Antoine Assistance Publique des Hôpitaux de Paris (APHP), Université Paris VI (Pierre et Marie Curie), 184 rue du Faubourg Saint-Antoine, 75012 Paris, France)

E-mail: jeremie.lefevre@aphp.fr

KEY WORDS 
Early rectal cancer - Lymph node metastasis - T1 rectal cancer - Submucosal invasion Surgery

\section{Abstract}

Aim: Only former studies, including colic and rectal cancers, exist on the prognosis of T1 tumours. Very few studies use Kikuchi's classification, dividing submucosa in 3 strata, to evaluate the depth of the submucosal invasion. This study aimed to assess the pathological risk factors for lymph nodes metastasis (LNM), pathologic and oncologic results of patients with early rectal cancer (ERC, pT1 tumour).

Methods: Between 2000 and 2014, 91 consecutive patients undergoing surgery (primary total mesorectal excision (TME) or local excision (LE) alone or LE followed by TME) for ERC were included.

Results: Surgery was LE for 18 patients, LE followed by TME for 22 and primary TME for 51 patients. After TME (n=73), 16 patients (23\%) had LNM. LNM rate was $15 \%, 14 \%$ and $30 \%$ for Sm1, Sm2 and Sm3 tumours. In multivariate analysis, lymphovascular invasion ( $\mathrm{p}=0.027)$ and high tumour budding $(\mathrm{p}=0.037)$ were the only independent factors of LNM. The depth of submucosal invasion was not associated with an increased risk of LNM. After a mean follow-up of $56 \pm 46$ months, 5-year overall survival, specific survival and disease-free survival were respectively $82 \%, 93 \%$ and $75 \%$. No significant difference of survival was found according to the depth of submucosal invasion or to the surgical management.

Conclusions: More than depth of submucosal invasion, histological features seem to be risk factors for LNM. Considering the LNM rate, TME should be discussed after local excision in terms of one of these pathological criteria.

\section{What does this paper add to the literature?}


We present one of the largest series of rectal pT1 tumours, assessing the risk of lymph node metastases based on several histological criteria. The depth of submucosal invasion is probably no longer a relevant factor when determining the risk of LNM. Total mesorectal excision (TME) should be discussed after histopathological examination of a local excision specimen in more terms of lymphovascular invasion and tumour budding. 


\section{INTRODUCTION}

Early rectal cancer (ERC) is defined as carcinoma that only invades the submucosa. This corresponds to a T1 tumour in the tumour-node-metastasis (TNM) classification ${ }^{1,2}$ and its incidence varies between 3 and $9 \%$ of all the resected colorectal cancers ${ }^{3-5}$. The management of ERC depends on the histopathological classification of the tumour, the depth of submucosal invasion and the risk of lymph node metastases (LNM). Often, the best plan is made retrospectively once the tumour has been removed and the histopathological stage confirmed.

Many studies have focused on the risk of lymphatic dissemination in ERC and possible risk factors of LNM have been studied including the depth of submucosal invasion, tumour location in the rectum, tumour budding, lymphovascular invasion, cribriform-type structural atypia and tumour size ${ }^{3,6-9}$. The reported overall rate of LNM varies between $6 \%$ and $29 \%$ 10,11. The main studies are listed in the Table $1^{3,5-33}$. LNM rate increases with the depth of submucosal invasion from 0 to $18 \%$ in $\mathrm{Sm} 1$ tumours, $0 \%$ to $25 \%$ in $\mathrm{Sm} 2$ and $12 \%$ to $38 \%$ in Sm3. Most seriesare however old and include a heterogeneous population of colonic and rectal tumours often of $\mathrm{T} 1$ and $\mathrm{T} 2$ stage. There is often no mention of the Kikuchi classification ${ }^{6}$. Furthermore, the two most recent studies, including only T1 rectal tumours, show that LNM rate is above $10 \%$, even for Sm1.

Curative treatment of rectal cancer is based on rectal resection with total mesorectal excision (TME). In the treatment of ERC, this may be overtreatment for patients with a low risk of LNM. Because of the risk of perioperative complications, the possibility of poor bowel function and mortality ${ }^{34-38}$, some patients have undergone local excision (LE) as the definitive surgical alternative. LE retains anal function and preservation of the organ but is associated with a potential risk of leaving involved lymph nodes behind. LE does indeed have fewer post-operative complications and a lower mortality but it does not offer oncologic 
results comparable to TME ${ }^{39}$. The choice of LE for a T1-Sm1 tumour and TME for a T1-Sm3 tumour is reasonably well established, but there is still controversy regarding the treatment of T1-Sm2 tumours and there are no clear guidelines. The present study aimed to assess the histopathological risk factors for LNM in pT1 rectal cancer and the cancer specific results after surgery.

\section{METHOD}

\section{Study population}

From January 2000 to December 2014, all consecutive patients who underwent a surgical resection for primary rectal adenocarcinoma in Saint-Antoine Hospital (Paris, France) were identified from a pathological prospective database. Only patients with a pT1 rectal cancer were included in the study. Synchronous colorectal cancers and those receiving neoadjuvant treatment with ypT1 tumour were excluded.

Demographic features (age, gender, body mass index), preoperative clinical features (American Society of Anesthesiologists score, tumour location), surgical features (procedure performed), pathological features including the pTNM classification, depth of submucosal invasion, the presence of vascular embolism and perineural invasion, margin involvement and long-term oncologic results (death, overall and disease free survival, locoregional recurrences and distant metastases) were collected retrospectively from a prospectively maintained database. Follow-up was assessed using medical files or by telephone interview with the general practitioner or the patient.

\section{Perioperative findings and surgery}

Preoperative assessment included digital rectal examination, endorectal ultrasound and/or magnetic resonance imaging (MRI). Surgery was by total mesorectal excision (TME) or local excision, according to the preoperative staging. 
Mesorectal excision is well described ${ }^{40,41}$. A laparoscopic approach was used according to the surgeon's practice but was systematically advocated. For a tumour in the upper third of the rectum, rectal dissection was carried out $5 \mathrm{~cm}$ below the lower border of the tumour with partial mesorectal excision and colorectal anastomosis (CRA). For a tumour in the mid or lower rectum, TME dissection was carried out to the pelvic floor and a coloanal anastomosis (CAA) performed. For rectal cancers located less than $10 \mathrm{~mm}$ from the dentate line, an abdominoperineal excision with permanent colostomy was performed. All extraperitoneal anastomoses were diverted by a defunctioning ileostomy.

Local excision (LE) was carried out in patients diagnosed with a $\mathrm{T} 1$ rectal cancer on preoperative endorectal ultrasound. It was performed either through transanal approach for very low rectal tumours or by transanal endoscopic microsurgery (TEM) for higher lesions. In the case of adverse histoipathological findings, LE was followed by radical surgery.

\section{Histopathologic examination}

Histopathologic examination of the resected specimen was performed according to a standardized protocol ${ }^{42}$ following the pTNM classification ${ }^{2}$. The depth of invasion into the submucosa was defined according to the Kikuchi classification (Sm1, Sm2 and Sm3) ${ }^{6}$. The circumferential resection margin was defined as positive if the primary tumour or an involved lymph node were found to be less than or equal to $1 \mathrm{~mm}$ from the margin of the specimen. The distal margin was considered R1 when invaded by tumour cells. Available histopathological slides were reviewed by a specialist intestinal histopathologist.

Tumour budding was defined as the presence of a isolated single cancer cells or a small cluster composed of fewer than five cancer cells scattered in the stroma at the advancing edge of the invasive tumour ${ }^{43}$. After choosing the block containing the highest degree of budding by standard diagnostic slide review, tumour buds were detected using a pan-cytokeratin AE1- 
AE3 stain (Dako, mouse monoclonal, 1:200, enzyme pretreatment 5 min; DAB chromogen)

44. More than ten buds per high-power-field (40x) were regarded as positive.

\section{Follow-up}

Adjuvant chemotherapy was discussed during a multidisciplinary meeting for patients with lymph node invasion on the histopathological examination. All patients were followed every three months during the first two years after surgery then every 6 months during the next three years and annually thereafter. During follow-up, the patients underwent clinical examination, a thoraco-abdomino-pelvic computerised tomographic (CT) scan and blood was taken for the estimation of carcinoembryonic antigen and carbohydrate antigen 19.9. Colonoscopy was performed one year after surgery, then every three years.

Locoregional recurrence was defined as recurrent disease within the pelvis, including recurrence at the site of the anastomosis and of the perineal wound. In cases with suspected locoregional recurrence, a pelvic MRI was performed and a pathological diagnosis of cancer was always confirmed by biopsy. Metastatic recurrence, diagnosed mainly by imaging, included liver metastasis, metastasis at other extra-abdominal sites and nodal metastasis beyond the regional nodes.

\section{Statistical analysis}

Data were presented as median \pm standard deviation (range) for quantitative data and as number of cases (percentage of cases) for categorical variables. Comparisons were carried out using, Student's t test and Pearson's $\chi^{2}$ or Fisher exact test as appropriate.

Survival was estimated using the Kaplan-Meier method and the log-rank test was used to compare survival curves. Overall survival was defined as the interval from the date of surgery to the date of death or the date of last follow-up for patients still alive. All causes of death, including postoperative deaths were considered for overall estimation of survival. All tests 
were two sided with a level of significance set at $\mathrm{p}<0.05$. All analyses were performed using JMP9 (SAS Institute Inc, Cary, NC, USA).

This study was conducted according to the ethical standards of the Committee on Human Experimentation of our institution and reported according to the Strengthening the Reporting of Observational Studies in Epidemiology (STROBE) guidelines ${ }^{45}$.

\section{RESULTS}

\section{Study population}

From January 2000 to December 2014, 121 consecutive patients with pT1 rectal cancer on histopathological examination of the excised specimen were operated on at Hôpital SaintAntoine, Paris. Of these, ten had a synchronous colorectal cancer. Twenty patients received neoajuvant treatment and were also excluded from the analysis. The remaining 91 patients with early rectal cancer were included in the study (Figure 1). The baseline characteristics of the population are given in Table 2 .

Fifty-one $(56 \%)$ patients were treated by a primary TME, $18(20 \%)$ underwent local excision (LE) alone and 22 (24\%) underwent LE followed by a secondary TME. Secondary surgery was performed: in two Sm1 patients $(\mathrm{n}=2 / 17,12 \%)$ owing to an $\mathrm{R} 1$ resection, in $12 \mathrm{Sm} 2$ patients $(n=12 / 18,67 \%)$, in six $\operatorname{Sm} 3$ patients $(n=6 / 8,75 \%)$ and for the two patients with unknown Sm status. The reasons for choosing not to perform a secondary TME in Sm2 and Sm3 patients were age over 75 years $(n=4)$, associated severe comorbidity $(n=7)$ and the absence of poor histopathological criteria in one Sm2 patient.

\section{Histopathological features}


The histopathological features are shown in Table 2. Macroscopic analysis showed piecemeal resection in nine (10\%) patients. This occurred only after LE: including three after endoscopic resection $(n=3 / 4,75 \%)$, five after transanal excision $(n=5 / 29,17 \%)$ and one after $\operatorname{TEM}(\mathrm{n}=1 / 7,14 \%)$.

The proportions of Kikuchi stages Sm1, Sm2 and Sm3 were 34\% (31), 32\% (29) and 32\% (29) $(32 \%)$. The depth of submucosal invasion could not be classified in $2(2 \%)$ patients. An R0 resection was achieved in $81(89 \%)$ patients and was R1 in the remaining ten $(11 \%)$ including two patients after LE and eight after TME. Five patients having a TME had circumferential involvement from a mesorectal involved lymph node, two patients had distal margin involvement and one had involvement of both circumferential and distal margins.

\section{Lymph node involvement}

Of the 73 patients with TME, lymph node status was known in 70 . The number of examined lymph nodes was 22 [8-167] per specimen. Sixteen (23\%) patients had lymph node metastases (Table 3). Patients with LNM had an average of $3 \pm 2$ [1-9] involved nodes. The node positive rate was $15 \%, 14 \%$ and $30 \%$ in $\mathrm{Sm} 1, \mathrm{Sm} 2$ and $\mathrm{Sm} 3$ patients $(\mathrm{p}=0.326)$.

Histomorphological parameters were evaluated for statistical correlation with LNM (Table 4). Univariate analysis showed that piece-meal resection $(\mathrm{p}=0.001)$, lymphovascular invasion $(\mathrm{p}=0.001)$ and high tumor budding $(\mathrm{p}=0.043)$ were associated with a significantly increased risk of LNM. The depth of submucosal invasion was not significantly associated with increased LNM. In multivariate logistic regression (Table 4), only lymphovascular invasion (Odds-Ratio $(\mathrm{OR})=6.3[1.2-50.8] ; \mathrm{p}=0.027)$ and high tumour budding $(\mathrm{OR}=7.6$ [1.1 - 152.2] ; $\mathrm{p}=0.037)$ were independent risk factors for LNM. Considering these two risk factors identified in multivariate analysis, we evaluated the risk of LNM according to the presence or absence of these risk factors in the same patient (Table 5). The risk was 0\% 
$(n=0 / 18)$ when there was no factor whatever the depth of submucosal invasion, and $36 \%$ $(n=14 / 39)$ when one or two factors were present.

\section{Survival analysis}

After a mean follow-up of $56 \pm 46$ [0-178] months, 10 (11\%) patients had died, including 4 (4\%) patients with cancer-related death. Nine (10\%) patients had developed recurrence including six with distant metastasis, two with local recurrence and one with both. The fiveyear overall survival (OS), specific survival (SS) and disease-free survival (DFS) were $82 \%$, $93 \%$ and $75 \%$. There was no statistical difference in five-year DFS, according to the surgical management $(\mathrm{p}=0.87)$ or the depth of submucosal invasion. $(\mathrm{p}=0.168)$ (Figure 2$)$.

\section{DISCUSSION}

In the present study, 91 patients with pT1 rectal cancers underwent surgery. After TME ( $\mathrm{n}=73)$, LNM were detected in $16(23 \%)$ patients. The rate of lymph node involvement was $15 \%, 14 \%$ and $30 \%$ in patients with $\mathrm{Sm} 1, \mathrm{Sm} 2$ and Sm3 tumours. In univariate analysis, lymphovascular invasion, piece-meal resection and a high degree of tumour budding were predictive factors for LNM. In multivariate analysis, lymphovascular invasion and high tumour budding were both independent risk factors. After a mean follow-up of 56 months, 10 (11\%) patients had died and nine (10\%) had recurrence, including three with local recurrence. The five-year overall survival (OS), specific survival (SS) and disease-free survival (DFS) were $82 \%, 93 \%$ and $75 \%$.

In the literature, many studies have focused on the prognosis of small colorectal cancers, especially pT1 tumours. These series include 5938 patients (Table 1) with an overall rate of LNM of $12 \%$ but over half of these had colonic cancer in which the LNM rate seems to be

higher than in the rectum ${ }^{6,8,46}$. Our literature review is in agreement with this report with a 
LNM rate of $13 \%$ and $10 \%$ in rectal and colonic cancers $(\mathrm{p}=0.009)$. ERC is different from early colonic cancer and LNM appear to be more common in these tumours. These results highlight the need for specific studies on ERC. Consequently, we present one of the largest series of specifically rectal pT1 tumours.

In our series, three of the 20 patients who underwent TME for a pT1-Sm1 tumour had LNM amounting to a rick of $15 \%$. These had unfavorable histopathological features such as lymphovascular invasion. This result is in contradiction with the initial rates published by Kikuchi, who found no case of LNM among the 35 patients with pT1-Sm1 rectal cancer ${ }^{6}$. Nevertheless, this publication is old and two more recent studies, including 55 and 68 patients with ERC, have also found a LNM rate above $10 \%$ for Sm1 tumours ${ }^{24,32}$. Despite the small sample size, these figures indicate nevertheless that the risk of lymph node involvement in Sm1 cancer may have been underestimated. For Sm2 tumours, no clear guidelines exist and the different therapeutic options are often discussed case by case. The $14 \%$ rate of LNM in the present study is consistent with the published data ${ }^{6,24,32}$. At least, one third of our patients with a Sm3 tumour had LNM. After LE, only two patients with Sm3 cancer did not n Have a subsequent TME, largely owing to comorbidity and age. One of these presented with local recurrence at six months. Total mesorectal excision is the gold standard for an Sm3 tumour and LE should be an exception, reserved for older patients and / or with serious comorbidity.

The results of the present study and of others indicate, therefore, that the depth of submucosal invasion is probably not a relevant factor to define the risk of LNM and determine the surgical management. Indeed, many studies have identified pathological criteria that are related to LNM and permit division into "high" or "low" risk. TME after a local excision should be discussed when the relevant these pathological features are present. For Sm3 tumours where the risk is $30 \%$, TME must be the basic ttreatment. IN the casse of $\mathrm{Sm} 2$ 
and $\mathrm{Sm} 1$ tumours, the rate of $\mathrm{LNM}$ is $0 \%$ when there are no risk factors and $36 \%$ when there is at least one. Consequently, the presence of a single poor histopathological factor on examination of an LE specimen, should lead to an immediate discussion of TME. Local excision should be reserved for patients with an Sm1 and Sm2 tumour when there is no lymphovascular invasion,tumour budding, piecemeal resection and tumour at the margin of the specimen ( $\mathrm{R} 1$ resection).

There has been much interest in ERC and its risk of LNM, but it is difficult to identify predictors of LNM with confidence, because of the heterogeneity of patients. In many studies, the number of patients is small and, some series include either colonic or rectal cancers or both and many combine pT1 and pT2 tumours. Subdivision of submucosal penetration may be irrelevant in many studies because location of tumour in the rectum ${ }^{6,8,46}$ and pT2 stage ${ }^{10 \text {, }}$ ${ }^{29,31}$ have been identified as undoubted factors associated with lymph node involvement. Only one study looked specifically at risk factors for LNM in early rectal cancer and none was demonstrated ${ }^{32}$. Lymphovascular invasion has been consistently reported in the literature to have high-risk of LNM in pT1 carcinoma ${ }^{8,9,12,14,24}$ and this was confirmed to be statistically significant in the present study in which, furthermore, tumours with lymphovascular invasion had deeper submucosal invasion than those without (data not shown). This could explain why in other series the depth of submucosal invasion and not lymphovascular invasion that seemed to increase the risk of LNM.

Another risk factor identified in the present study is piece-meal resection where there was a great difference in LNM for tumours removed piecemeal $(75 \%)$ or whole $(16 \%)$. The nine cases of piece-meal resection occurred after LE and eight of these had been operated on before 2011, mostly by endoscopic removal or trans-anal excision. All these patients, except one 80-year-old woman with cardiac comorbidity, had a subsequent TME at a median of 47 days after the LE [21-77]. Of these six had LNM and two did not. One patient died of 
metastatic disease in each of these groups. Piece-meal resection could cause release of cancer cells into the circulation with a metastatic potential favored by local trauma of the surgery. In the case of LE, a complete resection is a major quality criterion and given the availability of new surgical technologies. piecemeal excision should not be performed. For this reason, transanal endoscopic microsurgery (TEM) should be preferred to conventional transanal surgery whenever possible. Fragmentation of the tumour significantly less likely with TEM than with conventional transanal excision ${ }^{47-49}$. Recently, Clancy et al published a metaanalysis of six comparative studies, including 927 patients. This confirmed the superiority of the TEM over transanal excision in achieving complete monobloc resection $(\mathrm{OR}=0.096$, $\mathrm{p}<0.001)$ and $\mathrm{R} 0$ resection $(\mathrm{OR}=5.281, \mathrm{p}<0.001)$ and minimizing local recurrence $(\mathrm{OR}=0.248, \mathrm{p}<0.001)^{50}$.

Tumour budding is correlated with the risk of lymph node invasion and survival ${ }^{43,51}$. In a series of 56 patients with pT1 CRC, Kazama et al reported a LNM rate of $38 \%$ in the presence of budding and zero when it was absent $(\mathrm{p}=0.004)^{20}$. Similarly, in focusing specifically on ERC, Masaki et al showed that budding was not only a risk factor for LNM, but also for local recurrence after LE only of ERC $(p=0.048)^{52}$. Tumour budding would be important in the evaluation and surgical management of pT1 carcinoma, but the lack of standardized methods for its identification has been responsible for the low use. Tumour budding should be assessed after staining with a pan-cytokeratine antibody as in the present study; this greatly improves the identification of buds ${ }^{16}$. Using this method, our results are concordant with those reported by Ueno et al [16]. One of the weaknesses of our study is the lack of multivariate analysis, but the small size of the groups do not allow a valid analysis.

The current study used three surgical strategies for treating ERC including primary TME, LE alone and LE followed by salvage TME. No significant difference was found between them in the risk of regional LNM or survival. In the current era of 'organ 
preservation', LE is attractive as it avoids the morbidity of the TME and preserves satisfactory bowel function. Two meta-analyses have shown superiority of LE, compared with TME, in various end points including postoperative morbidity ( $8 \%$ vs. $47 \%, \mathrm{p}=0.01$ ), major postoperative morbidity ( $4 \%$ vs. $16 \%, \mathrm{p}<0.001)$ and mortality $(0.4 \% \text { vs. } 2 \%, \mathrm{p}=0.005)^{39,53}$, but on the other hand LE offers poorer oncologic results owing to the risk of involved nodes in the mesorectum which are not removed by the surgery. This results in lower overall and cancer-specific survival ( $>>0.001)$ and higher local recurrence rates than TME. The absence of a significant difference in our study may be related to the small size of the groups despite a 14-year study period, and secondly to the rigorous selection of patients for LE.

In conclusion, we highlight the specific natural history of ERC with a higher rate of regional lymph node involvement than in early colon cancer. Contrary to the findings of Kikuchi et al [6] the depth of submucosal invasion does not predict the presence of LNM in ERC. Other histopathological factors, such as lymphovascular invasion and budding are the best histopathological indicators of regional lymphadenopathy. 


\section{REFERENCES}

1. Tytherleigh MG, Warren BF, Mortensen NJ. Management of early rectal cancer. $\mathrm{Br} J$ Surg 2008; 95(4):409-23.

2. Sobin LH, Compton CC. TNM seventh edition: what's new, what's changed: communication from the International Union Against Cancer and the American Joint Committee on Cancer. Cancer 2010; 116(22):5336-9.

3. Nascimbeni R, Burgart LJ, Nivatvongs S, et al. Risk of lymph node metastasis in T1 carcinoma of the colon and rectum. Dis Colon Rectum 2002; 45(2):200-6.

4. Guillou PJ, Quirke P, Thorpe H, et al. Short-term endpoints of conventional versus laparoscopic-assisted surgery in patients with colorectal cancer (MRC CLASICC trial): multicentre, randomised controlled trial. Lancet 2005; 365(9472):1718-26.

5. Huddy SP, Husband EM, Cook MG, et al. Lymph node metastases in early rectal cancer. Br J Surg 1993; 80(11):1457-8.

6. Kikuchi R, Takano M, Takagi K, et al. Management of early invasive colorectal cancer. Risk of recurrence and clinical guidelines. Dis Colon Rectum 1995; 38(12):1286-95.

7. Kitajima K, Fujimori T, Fujii S, et al. Correlations between lymph node metastasis and depth of submucosal invasion in submucosal invasive colorectal carcinoma: a Japanese collaborative study. J Gastroenterol 2004; 39(6):534-43.

8. Okabe S, Shia J, Nash G, et al. Lymph node metastasis in T1 adenocarcinoma of the colon and rectum. J Gastrointest Surg 2004; 8(8):1032-9; discussion 1039-40.

9. Egashira Y, Yoshida T, Hirata I, et al. Analysis of pathological risk factors for lymph node metastasis of submucosal invasive colon cancer. Mod Pathol 2004; 17(5):50311.

10. Sitzler PJ, Seow-Choen F, Ho YH, et al. Lymph node involvement and tumor depth in rectal cancers: an analysis of 805 patients. Dis Colon Rectum 1997; 40(12):1472-6.

11. Landmann RG, Wong WD, Hoepfl J, et al. Limitations of early rectal cancer nodal staging may explain failure after local excision. Dis Colon Rectum 2007; 50(10):15205.

12. Brodsky JT, Richard GK, Cohen AM, et al. Variables correlated with the risk of lymph node metastasis in early rectal cancer. Cancer 1992; 69(2):322-6.

13. Tanaka S, Haruma K, Teixeira CR, et al. Endoscopic treatment of submucosal invasive colorectal carcinoma with special reference to risk factors for lymph node metastasis. J Gastroenterol 1995; 30(6):710-7.

14. Bayar S, Saxena R, Emir B, et al. Venous invasion may predict lymph node metastasis in early rectal cancer. Eur J Surg Oncol 2002; 28(4):413-7.

15. Shimomura T, Ishiguro $\mathrm{S}$, Konishi $\mathrm{H}$, et al. New indication for endoscopic treatment of colorectal carcinoma with submucosal invasion. J Gastroenterol Hepatol 2004; 19(1):48-55.

16. Ueno $\mathrm{H}$, Mochizuki $\mathrm{H}$, Hashiguchi $\mathrm{Y}$, et al. Risk factors for an adverse outcome in early invasive colorectal carcinoma. Gastroenterology 2004; 127(2):385-94.

17. Yamamoto S, Watanabe $\mathrm{M}$, Hasegawa $\mathrm{H}$, et al. The risk of lymph node metastasis in T1 colorectal carcinoma. Hepatogastroenterology 2004; 51(58):998-1000.

18. Bentrem DJ, Okabe S, Wong WD, et al. T1 adenocarcinoma of the rectum: transanal excision or radical surgery? Ann Surg 2005; 242(4):472-7; discussion 477-9.

19. Wang HS, Liang WY, Lin TC, et al. Curative resection of T1 colorectal carcinoma: risk of lymph node metastasis and long-term prognosis. Dis Colon Rectum 2005; 48(6):1182-92. 
20. Kazama S, Watanabe T, Ajioka Y, et al. Tumour budding at the deepest invasive margin correlates with lymph node metastasis in submucosal colorectal cancer detected by anticytokeratin antibody CAM5.2. Br J Cancer 2006; 94(2):293-8.

21. Choi PW, Yu CS, Jang SJ, et al. Risk factors for lymph node metastasis in submucosal invasive colorectal cancer. World J Surg 2008; 32(9):2089-94.

22. Yasuda K, Inomata M, Shiromizu A, et al. Risk factors for occult lymph node metastasis of colorectal cancer invading the submucosa and indications for endoscopic mucosal resection. Dis Colon Rectum 2007; 50(9):1370-6.

23. Sohn DK, Chang HJ, Park JW, et al. Histopathological risk factors for lymph node metastasis in submucosal invasive colorectal carcinoma of pedunculated or semipedunculated type. J Clin Pathol 2007; 60(8):912-5.

24. Rasheed S, Bowley DM, Aziz O, et al. Can depth of tumour invasion predict lymph node positivity in patients undergoing resection for early rectal cancer? A comparative study between T1 and T2 cancers. Colorectal Dis 2008; 10(3):231-8.

25. Son HJ, Song SY, Lee WY, et al. Characteristics of early colorectal carcinoma with lymph node metastatic disease. Hepatogastroenterology 2008; 55(85):1293-7.

26. Yamauchi H, Togashi K, Kawamura YJ, et al. Pathological predictors for lymph node metastasis in T1 colorectal cancer. Surg Today 2008; 38(10):905-10.

27. Tateishi Y, Nakanishi Y, Taniguchi H, et al. Pathological prognostic factors predicting lymph node metastasis in submucosal invasive (T1) colorectal carcinoma. Mod Pathol 2010; 23(8):1068-72.

28. Komori K, Hirai T, Kanemitsu Y, et al. Is "depth of submucosal invasion $>$ or $=1,000$ microm" an important predictive factor for lymph node metastases in early invasive colorectal cancer (pT1)? Hepatogastroenterology 2010; 57(102-103):1123-7.

29. Kobayashi $\mathrm{H}$, Mochizuki $\mathrm{H}$, Kato $\mathrm{T}$, et al. Is total mesorectal excision always necessary for T1-T2 lower rectal cancer? Ann Surg Oncol 2010; 17(4):973-80.

30. Salinas HM, Dursun A, Klos CL, et al. Determining the need for radical surgery in patients with T1 rectal cancer. Arch Surg 2011; 146(5):540-3.

31. Saraste D, Gunnarsson U, Janson M. Predicting lymph node metastases in early rectal cancer. Eur J Cancer 2013; 49(5):1104-8.

32. Kulu Y, Muller-Stich BP, Bruckner T, et al. Radical surgery with total mesorectal excision in patients with T1 rectal cancer. Ann Surg Oncol 2015; 22(6):2051-8.

33. Kawachi H, Eishi Y, Ueno H, et al. A three-tier classification system based on the depth of submucosal invasion and budding/sprouting can improve the treatment strategy for T1 colorectal cancer: a retrospective multicenter study. Mod Pathol 2015; 28(6):872-9.

34. Peeters KC, Tollenaar RA, Marijnen CA, et al. Risk factors for anastomotic failure after total mesorectal excision of rectal cancer. Br J Surg 2005; 92(2):211-6.

35. Averbach AM, Chang D, Koslowe P, et al. Anastomotic leak after double-stapled low colorectal resection. Dis Colon Rectum 1996; 39(7):780-7.

36. Hendren SK, O'Connor BI, Liu M, et al. Prevalence of male and female sexual dysfunction is high following surgery for rectal cancer. Ann Surg 2005; 242(2):21223.

37. Maurer CA, Z'Graggen K, Renzulli P, et al. Total mesorectal excision preserves male genital function compared with conventional rectal cancer surgery. Br J Surg 2001; 88(11):1501-5.

38. Kakodkar R, Gupta S, Nundy S. Low anterior resection with total mesorectal excision for rectal cancer: functional assessment and factors affecting outcome. Colorectal Dis 2006; 8(8):650-6. 
39. Kidane B, Chadi SA, Kanters S, et al. Local resection compared with radical resection in the treatment of T1N0M0 rectal adenocarcinoma: a systematic review and metaanalysis. Dis Colon Rectum 2015; 58(1):122-40.

40. Bennis M, Parc Y, Lefevre JH, et al. Morbidity risk factors after low anterior resection with total mesorectal excision and coloanal anastomosis: a retrospective series of 483 patients. Ann Surg 2012; 255(3):504-10.

41. Tranchart H, Lefevre JH, Svrcek M, et al. What is the incidence of metastatic lymph node involvement after significant pathologic response of primary tumor following neoadjuvant treatment for locally advanced rectal cancer? Ann Surg Oncol 2013; 20(5):1551-9.

42. Washington MK, Berlin J, Branton P, et al. Protocol for the examination of specimens from patients with primary carcinoma of the colon and rectum. Arch Pathol Lab Med 2009; 133(10):1539-51.

43. Prall F. Tumour budding in colorectal carcinoma. Histopathology 2007; 50(1):151-62.

44. Koelzer VH, Zlobec I, Berger MD, et al. Tumor budding in colorectal cancer revisited: results of a multicenter interobserver study. Virchows Arch 2015; 466(5):485-93.

45. von Elm E, Altman DG, Egger M, et al. The Strengthening the Reporting of Observational Studies in Epidemiology (STROBE) statement: guidelines for reporting observational studies. Lancet 2007; 370(9596):1453-7.

46. Okuyama T, Oya M, Ishikawa H. Budding as a risk factor for lymph node metastasis in pT1 or pT2 well-differentiated colorectal adenocarcinoma. Dis Colon Rectum 2002; 45(5):628-34.

47. Christoforidis D, Cho HM, Dixon MR, et al. Transanal endoscopic microsurgery versus conventional transanal excision for patients with early rectal cancer. Ann Surg 2009; 249(5):776-82.

48. De Graaf EJ, Doornebosch PG, Tollenaar RA, et al. Transanal endoscopic microsurgery versus total mesorectal excision of $\mathrm{T} 1$ rectal adenocarcinomas with curative intention. Eur J Surg Oncol 2009; 35(12):1280-5.

49. Moore JS, Cataldo PA, Osler T, et al. Transanal endoscopic microsurgery is more effective than traditional transanal excision for resection of rectal masses. Dis Colon Rectum 2008; 51(7):1026-30; discussion 1030-1.

50. Clancy C, Burke JP, Albert MR, et al. Transanal endoscopic microsurgery versus standard transanal excision for the removal of rectal neoplasms: a systematic review and meta-analysis. Dis Colon Rectum 2015; 58(2):254-61.

51. Kanazawa H, Mitomi H, Nishiyama Y, et al. Tumour budding at invasive margins and outcome in colorectal cancer. Colorectal Dis 2008; 10(1):41-7.

52. Masaki T, Matsuoka H, Sugiyama M, et al. Budding as a useful determinant of the optimal treatment for $\mathrm{T} 1$ rectal carcinomas. Hepatogastroenterology 2003; 50(50):388-91.

53. $\mathrm{Wu} \mathrm{Y,} \mathrm{Wu} \mathrm{YY,} \mathrm{Li} \mathrm{S,} \mathrm{et} \mathrm{al.} \mathrm{TEM} \mathrm{and} \mathrm{conventional} \mathrm{rectal} \mathrm{surgery} \mathrm{for} \mathrm{T1} \mathrm{rectal} \mathrm{cancer:}$ a meta-analysis. Hepatogastroenterology 2011; 58(106):364-8. 
Table 1: Review of the literature of colorectal $\mathrm{T} 1$ carcinoma and lymph node involvement

\begin{tabular}{|c|c|c|c|c|c|c|c|}
\hline \multirow{2}{*}{ Authors } & \multirow{2}{*}{ Year } & \multirow{2}{*}{ Tumor localisation } & \multirow{2}{*}{ Patients } & \multicolumn{4}{|c|}{ Lymph node involvement rate } \\
\hline & & & & $\mathrm{N}+$ & $\mathrm{Sm} 1$ & $\mathrm{Sm} 2$ & $\mathrm{Sm} 3$ \\
\hline Brodsky et al. & 1992 & Rectum & 26 & $3(12 \%)$ & - & - & - \\
\hline Huddy et al. & 1993 & Rectum & 27 & $3(11 \%)$ & - & - & - \\
\hline Kikuchi et al. & 1995 & Colon - Rectum & 182 & $13(7 \%)$ & $0 / 64(0 \%)$ & $4 / 82(5 \%)$ & $9 / 36(25 \%)$ \\
\hline Tanaka et al. & 1995 & Colon - Rectum & 177 & $21(12 \%)$ & - & $(4 \%)$ & $(20 \%)$ \\
\hline Sitzler et al. & 1997 & Rectum & 35 & $2(6 \%)$ & - & - & - \\
\hline Nascimbeni et al. & 2002 & Colon - Rectum & 353 & $46(13 \%)$ & $2 / 70(3 \%)$ & $9 / 120(8 \%)$ & $35 / 154(23 \%)$ \\
\hline Bayar et al. & 2002 & Rectum & 59 & $5(8 \%)$ & - & - & \\
\hline Kitajima et al. & 2004 & Colon - Rectum & 865 & $87(10 \%)$ & - & - & - \\
\hline Okabe et al. & 2004 & Colon - Rectum & 428 & $43(10 \%)$ & - & - & - \\
\hline Shimomura et al. & 2004 & Colon - Rectum & 171 & $18(10 \%)$ & - & - & - \\
\hline Egashira et al. & 2004 & Colon - Rectum & 140 & $13(9 \%)$ & - & - & - \\
\hline Ueno et al. & 2004 & Colon - Rectum & 251 & $33(13 \%)$ & - & - & - \\
\hline Yamamoto et al. & 2004 & Colon - Rectum & 301 & $19(6 \%)$ & - & - & - \\
\hline Bentrem et al. & 2005 & Rectum & 168 & $31(18 \%)$ & - & - & - \\
\hline Wang et al. & 2005 & Colon - Rectum & 159 & $16(10 \%)$ & $2 / 70(3 \%)$ & $3 / 46(6 \%)$ & $11 / 43(26 \%)$ \\
\hline Kazama et al. & 2006 & Colon - Rectum & 56 & $8(14 \%)$ & - & - & - \\
\hline Landmann et al. & 2007 & Rectum & 21 & $6(29 \%)$ & - & - & - \\
\hline Sohn et al. & 2007 & Colon - Rectum & 48 & $7(15 \%)$ & $4 / 22(18 \%)$ & $1 / 13(8 \%)$ & $2 / 13(15 \%)$ \\
\hline Yasuda et al. & 2007 & Colon - Rectum & 86 & $21(24 \%)$ & - & - & - \\
\hline Choi et al. & 2008 & Colon - Rectum & 168 & $24(14 \%)$ & $4 / 95(4 \%)$ & $10 / 47(21 \%)$ & $10 / 26(38 \%)$ \\
\hline Rasheed et al. & 2008 & Rectum & 55 & $7(13 \%)$ & $2 / 15(13 \%)$ & $1 / 7(14 \%)$ & $4 / 33(12 \%)$ \\
\hline Son et al. & 2008 & Colon - Rectum & 147 & $25(17 \%)$ & & & \\
\hline Yamauchi et al. & 2008 & Colon - Rectum & 164 & $16(10 \%)$ & - & - & - \\
\hline Tateishi et al. & 2010 & Colon - Rectum & 322 & $46(14 \%)$ & - & - & - \\
\hline Komori et al. & 2010 & Colon - Rectum & 111 & $17(15 \%)$ & - & - & - \\
\hline Kobayashi et al. & 2010 & Rectum & 233 & $20(9 \%)$ & - & - & - \\
\hline Salinas et al. & 2011 & Rectum & 35 & $4(11 \%)$ & - & - & - \\
\hline
\end{tabular}




\begin{tabular}{|c|c|c|c|c|c|c|c|}
\hline $\begin{array}{l}\text { Saraste et al. } \\
\text { Kulu et al. } \\
\text { Kawachi et al. }\end{array}$ & $\begin{array}{l}2013 \\
2015 \\
2015 \\
\end{array}$ & $\begin{array}{l}\text { Rectum } \\
\text { Rectum } \\
\text { Colon - Rectum }\end{array}$ & $\begin{array}{r}205 \\
68 \\
806 \\
\end{array}$ & $\begin{array}{r}24(12 \%) \\
9(13 \%) \\
97(12 \%) \\
\end{array}$ & $2 / 17(12 \%)$ & $4 / 16(25 \%)$ & $3 / 22(14 \%)$ \\
\hline & & Colon & 1816 & $189(10 \%)^{*}$ & $0 / 29(0 \%)$ & $0 / 40(0 \%)$ & $2 / 10(20 \%)$ \\
\hline & & Rectum & 2151 & $283(13 \%)^{*}$ & $4 / 67(6 \%)$ & $9 / 65(14 \%)$ & $14 / 81(17 \%)$ \\
\hline & & Total & 5938 & $722(12 \%)$ & $16 / 353(5 \%)$ & $32 / 331(10 \%)$ & $74 / 327(23 \%)$ \\
\hline
\end{tabular}


Table 2: Characteristics and histopathological features of 91 patients with early rectal cancer (ERC)

TME total mesorectal excision

CRA colorectal anastomosis

\begin{tabular}{|c|c|}
\hline & $\begin{array}{c}\text { Early Rectal Cancer (pT1) } \\
\qquad \mathrm{n}=91\end{array}$ \\
\hline Male & $65(71 \%)^{(a)}$ \\
\hline Age & $62 \pm 12^{(b)}$ \\
\hline Body Mass Index & $26 \pm 4$ \\
\hline \multicolumn{2}{|l|}{ ASA $^{(c)}$ score } \\
\hline I-II & $77(85 \%)$ \\
\hline III-IV & $14(15 \%)$ \\
\hline \multicolumn{2}{|l|}{ Digestive comorbidity } \\
\hline Familial adenoma polyposis & $2(2 \%)$ \\
\hline Inflammatory bowel disease & $3(3 \%)$ \\
\hline \multicolumn{2}{|l|}{ Tumour location } \\
\hline Upper rectum & $12(13 \%)$ \\
\hline Middle rectum & $19(21 \%)$ \\
\hline Lower rectum & $50(55 \%)$ \\
\hline Unknown (polyposis) & $10(11 \%)$ \\
\hline \multicolumn{2}{|l|}{ Pre-operative tumour stage } \\
\hline Stage I (T1/T2 N0) & $48(53 \%)$ \\
\hline Stage II (T3/T4 N0) & $1(1 \%)$ \\
\hline Stage III $(\mathrm{N}+)$ & $6(7 \%)$ \\
\hline Stage IV (Synchronous metastasis) & $2(2 \%)$ \\
\hline Unknown & $34(37 \%)$ \\
\hline \multicolumn{2}{|l|}{ Surgical procedure } \\
\hline Endoscopic resection & $4(4 \%)$ \\
\hline Local excision & $36(40 \%)$ \\
\hline Transanal excision & 29 \\
\hline $\mathrm{TEM}^{(\mathrm{d})}$ & 7 \\
\hline$T M E^{(\mathrm{e})}$ & $73(80 \%)$ \\
\hline Proctectomy with CRA ${ }^{(\mathrm{f})}$ & 10 \\
\hline TME with CAA ${ }^{(g)}$ & 47 \\
\hline Ileo-pouch anal anastomosis & 12 \\
\hline Hartmann procedure & 1 \\
\hline Abdominoperineal excision & 1 \\
\hline Adjuvant chemotherapy & $12(13 \%)$ \\
\hline Tumour size (mm) & $23 \pm 14$ \\
\hline Polypoid tumour & $36(39 \%)$ \\
\hline
\end{tabular}




\begin{tabular}{|l|c|} 
Piecemeal excision & $9(10 \%)$ \\
Histopathological grade & \\
Well - Moderate & $80(88 \%)$ \\
Poor & $4(4 \%)$ \\
Unknown & $7(8 \%)$ \\
Depth of submucosal invasion & \\
Sm1 & $31(34 \%)$ \\
Sm2 & $29(32 \%)$ \\
Sm3 & $29(32 \%)$ \\
Unknown & $2(2 \%)$ \\
Lymphovascular invasion & $30(33 \%)$ \\
Perineural invasion & $2(2 \%)$ \\
Tumour budding & \\
None & $13(14 \%)$ \\
Low & $19(21 \%)$ \\
High & $35(38 \%)$ \\
R1 resection & $10(11 \%)$ \\
\hline
\end{tabular}

(a) number of patients (percentage); (b) mean \pm standard deviation; (c) American society of anesthesiology grade; (d) transanal endocopic microsurgery; (e) total mesorectal excision; (f) colorectal anastomosis; (g) coloanal anastomosis. 
Table 3: Histopathological features of the primary tumour in 16 patients with lymph node metastasis

\begin{tabular}{|c|c|c|c|c|c|c|c|c|c|c|c|c|c|c|c|}
\hline & Sex & Age & $\begin{array}{l}\text { Tumour } \\
\text { location }\end{array}$ & Polypoid & $\begin{array}{c}\text { Diameter } \\
(\mathbf{m m})\end{array}$ & $\begin{array}{c}\text { Primary } \\
\text { LE }^{(a)}\end{array}$ & $\begin{array}{l}\text { Piece- } \\
\text { Meal }\end{array}$ & $\begin{array}{c}\text { Histological } \\
\text { Grade }\end{array}$ & $\mathrm{Sm}$ & $\begin{array}{c}\text { Lymphovascular } \\
\text { invasion }\end{array}$ & $\begin{array}{c}\text { Perineural } \\
\text { invasion }\end{array}$ & $\begin{array}{l}\text { Tumour } \\
\text { budding }\end{array}$ & $\begin{array}{l}\text { R0 } \\
\text { R1 }\end{array}$ & Recurrence & Survival \\
\hline 1 & $\mathrm{M}$ & 76 & Upper & No & 15 & - & - & Moderate & Sm1 & Yes & Yes & High & 1 & Distant & Dead \\
\hline 2 & M & 19 & - & Yes & 4 & - & - & Well & Sm1 & Yes & No & High & 0 & - & Alive \\
\hline 3 & M & 63 & Low & No & 10 & TEM $^{(b)}$ & No & Moderate & Sm1 & Yes & No & Low & 1 & - & Alive \\
\hline 4 & M & 59 & Low & No & 40 & Transanal & Yes & Well & $\mathrm{Sm} 2$ & Yes & No & & 0 & - & Alive \\
\hline 5 & M & 72 & Low & No & 12 & Transanal & Yes & Well & $\mathrm{Sm} 2$ & No & No & & 0 & - & Alive \\
\hline 6 & $\mathrm{~F}$ & 42 & Middle & No & 23 & Transanal & Yes & Well & $\mathrm{Sm} 2$ & Yes & No & & 0 & - & Alive \\
\hline 7 & $\mathrm{~F}$ & 43 & Low & No & 25 & - & - & Moderate & $\mathrm{Sm} 3$ & Yes & No & High & 0 & - & Alive \\
\hline 8 & M & 67 & Upper & Yes & 30 & Endoscopy & Yes & Moderate & $\mathrm{Sm} 3$ & Yes & No & None & 0 & Distant & Dead \\
\hline 9 & $\mathrm{~F}$ & 56 & Middle & No & 30 & - & - & Moderate & $\mathrm{Sm} 3$ & Yes & No & High & 1 & - & Alive \\
\hline 10 & M & 60 & Middle & No & 30 & - & - & Moderate & $\mathrm{Sm} 3$ & Yes & No & High & 0 & - & Alive \\
\hline 11 & M & 72 & Upper & No & - & Transanal & Yes & Well & Sm3 & Yes & No & High & 0 & - & Alive \\
\hline 12 & M & 53 & Low & Yes & 25 & - & - & Well & Sm3 & No & No & High & 0 & $\begin{array}{l}\text { Distant and } \\
\text { Local }\end{array}$ & Dead \\
\hline 13 & $\mathrm{M}$ & 41 & - & Yes & 20 & - & - & Poor & Sm3 & No & No & & 0 & - & Alive \\
\hline 14 & $\mathrm{~F}$ & 68 & Low & No & 75 & - & - & Moderate & Sm3 & Yes & No & High & 0 & Distant & Alive \\
\hline 15 & $\mathrm{~F}$ & 51 & Low & Yes & 15 & Endoscopy & Yes & Well & $\begin{array}{l}\text { Unkno } \\
\text { wn }\end{array}$ & Yes & No & & 1 & - & Alive \\
\hline 16 & $\mathrm{~F}$ & 61 & Middle & Yes & 20 & - & - & Moderate & $\begin{array}{c}\text { Unkno } \\
\text { wn }\end{array}$ & No & No & High & 0 & - & Alive \\
\hline
\end{tabular}

(a) local excision; (b) transanal endoscopic microsurgery 
Table 4: Univariate and multivariate analysis of risk factors for lymph node metastasis in 70 patients undergoing TME for early rectal cancer

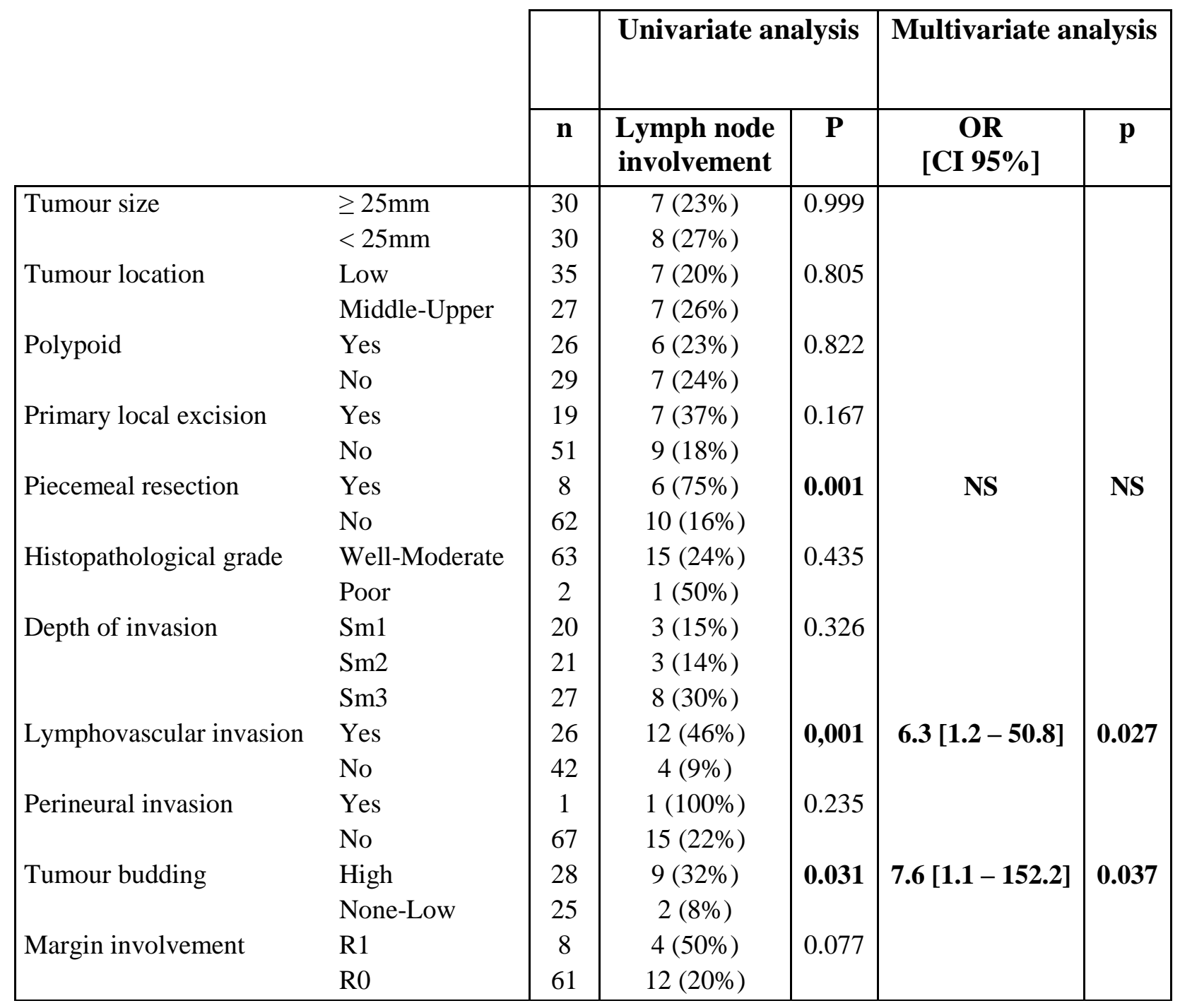

(a) lymph node metastasis 
Table 5: Rate of lymph node metastasis according to the presence or absence of risk factors including lymphovascular invasion and tumour budding.

\begin{tabular}{lcc}
\hline & $\begin{array}{c}\text { No risk } \\
\text { factor }\end{array}$ & $\begin{array}{c}\text { One or 2 } \\
\text { risk factors }\end{array}$ \\
\hline Overall & $0 / 18(0 \%)$ & $14 / 39(36 \%)$ \\
Depth of submucosal invasion & & \\
Sm 1 & $0 / 8(0 \%)$ & $3 / 6(50 \%)$ \\
Sm 2 & $0 / 8(0 \%)$ & $2 / 10(20 \%)$ \\
Sm 3 & $0 / 2(0 \%)$ & $7 / 21(33 \%)$ \\
Unknown & - & $2 / 2(100 \%)$ \\
\hline
\end{tabular}




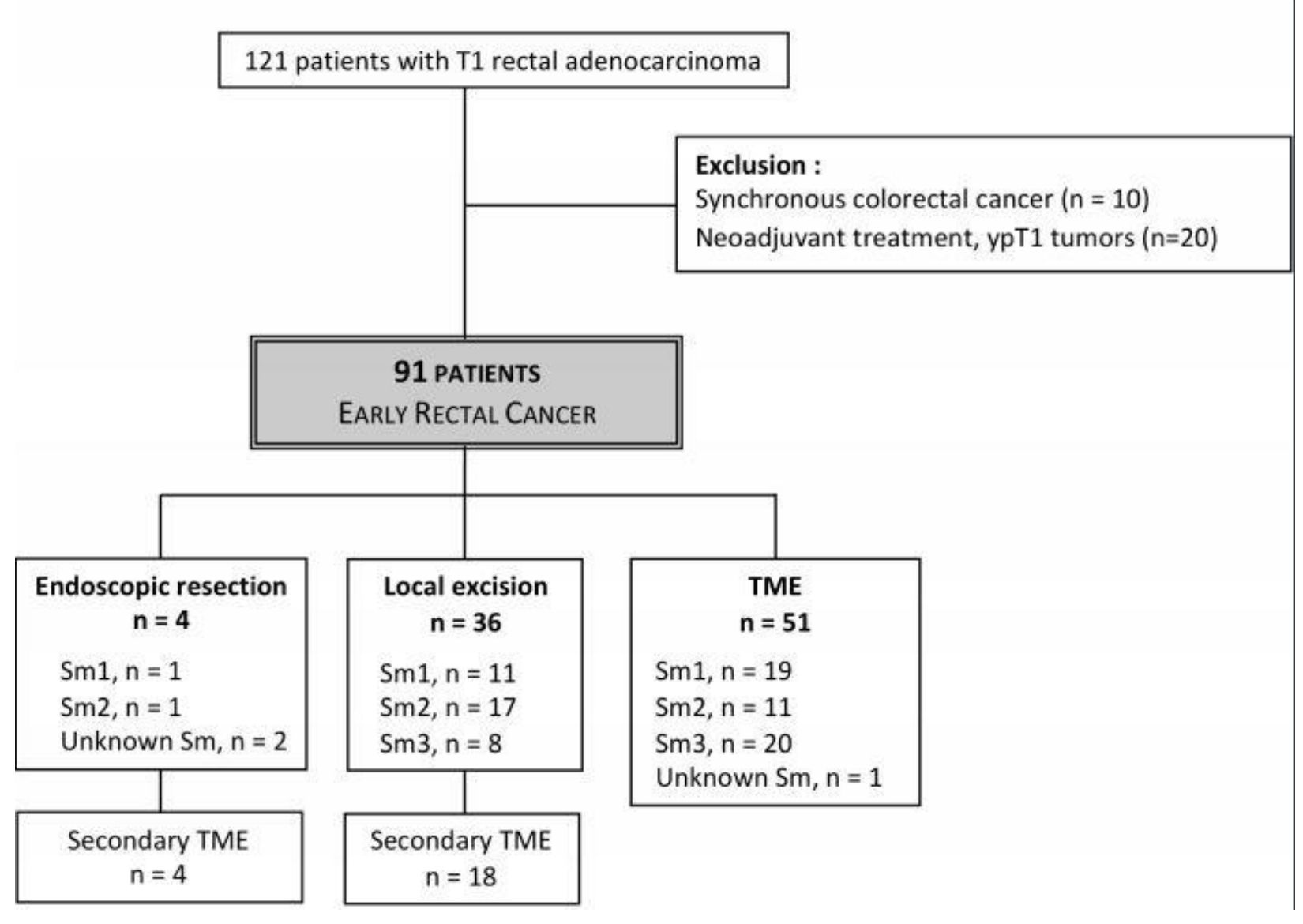

Figure 1: Flow-diagram of 121 patients with pT1 rectal cancer. 


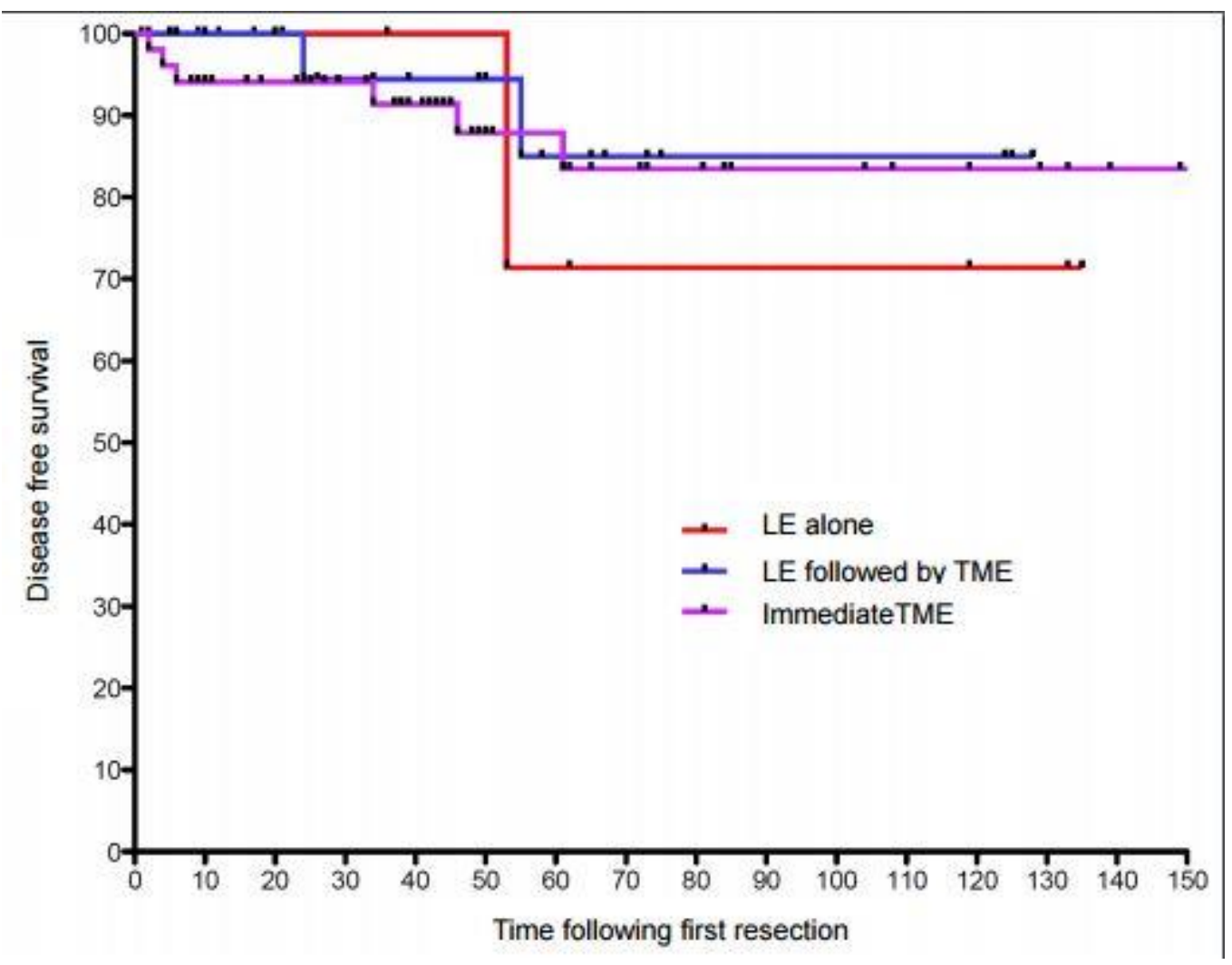

Fig $2 \mathrm{~A}$

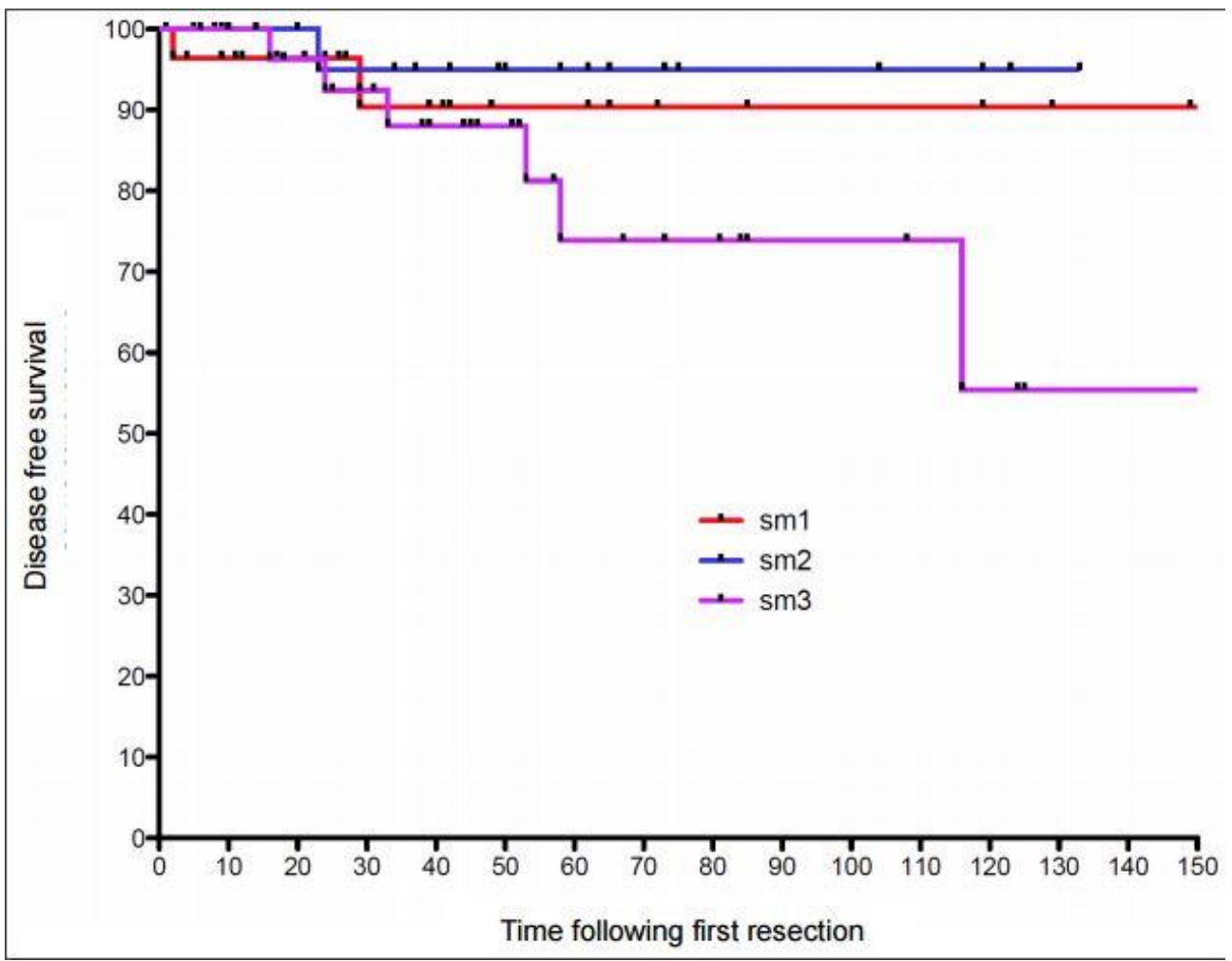

Fig 2B

Figure 2: Kaplan-Meier curves of disease-free survival, according to the surgical management $(A)$ and the depth of submucosal invasion (B) 